\title{
Private capital in the rural development programme: the case of the Apulia Region, Southern Italy
}

Donatello Caruso

(corresponding author)

University of Foggia,

Italy

E-mail: donatello.caruso@unifg.it

Francesco Conto

University of Foggia, Italy

Keywords:

EU Rural Development

Programme,

Apulia region Italy,

generalised propensity score,

public aid in agriculture,

private capital
This study analyses the role of private capital in modernising agricultural holdings, as implemented by the Rural Development Programme (RDP). Specifically the authors refer to the Measure 121 (Axes I) of the RDP 20072013, as decided by the Apulia Region; the main aim of this measure, in accordance with Art. 20(b)(i) of Council Regulation (EC) No. $1698 / 2005$, is the modernisation of agricultural holdings through grants to be invested in farm machinery and equipment. The aim of this work is to verify how private capital (co-financing) that an agricultural holding is willing to invest influences the amount of public aid received. Leveraging the generalised propensity score (GPS) method, a doseresponse function is estimated based on a dataset of Apulia farms. The results highlight the influence of private capital in increasing the probability of firms being granted public aid.

\section{Introduction}

In European funding contests, evaluations of investment projects and their sustainability over time are important in making business management decisions. As noted in some official reports and scientific works, observations as to whether European Union (EU) aid earmarked for modernising agricultural holdings has been directed to EU priorities and the specific needs of EU member states has been a relevant issue (European Court of Auditors 2012, Lukesch-Schuh 2010). Additionally, researchers such as Materia et al. (2015) have investigated the role of scientific merit in the peer-review-based selection process, specifically for agricultural research projects. Importantly, our study is among the first to investigate the role of private capital (i.e. co-financing) being invested in agricultural holdings, relative to the amount of public aid received for an agricultural holding modernisation project. This work analyses in particular the influence of private capital on the RDP between 2007 and 2013 on Apulia agricultural holdings. As part of the RDP, a programming document was prepared by EU member states, with the aim of planning and implementing the EU's rural development policy; this document has been approved by 
the European Commission (EC). An RDP document can be prepared at regional or national level; in the case of Italy, one has been prepared by each region, and the measures therein define the rules according to which projects can be financed within an axis.

The EU finances investment projects with respect to agricultural holdings, through the enactment of its rural development policy. In the most recent programming period (i.e. 2007-2013), EUR11.1 billion (as of January 2012) was budgeted for a specific investment measure called the 'modernisation of agricultural holdings'. EU funding was complemented by national public expenditures to cover part of the total investment cost. In this context, the Apulia Region adopted the measure devoted to the reorganisation and modernisation of regional agricultural holdings. That measure - namely, Measure 121 (Axes I) of the RDP - aims to modernise agricultural holdings by offering subsidies that can be invested in farm machinery and equipment (e.g. tractors, harvesters, farm buildings, manure storage, irrigation facilities); this measure is executed in accordance with Art. 20(b)(i) of Council Regulation (EC) No. 1698/2005. In particular, policy intervention within the context of this measure entails a co-financing mechanism, on the basis of which private capital is called for covering at least 30\% of the amount proposed as an investment. The remaining percentage represents the maximum quota of nonrepayable public subsidies given in support of private capital.

Most of the recent policy impact evaluation literature has focused on evaluating the causal effects of a binary treatment. One stream of the literature pertains to propensity-score matching (i.e. comparing the income of companies participating in a project with that of non-participating companies with similar characteristics). According to Imbens (2000) and Lechner (2001), extended propensity-score matching can be used to employ a categorical treatment variable. Hirano and Imbens (2004) introduced the concept of the GPS and extended the results of Rosenbaum and Rubin (1983) to a continuous-treatment case. In the current study, beginning with the consideration of the first public call, public aid levels differ depending on the level of private capital; therefore, we consider as a treatment variable private capital - and public aid as an outcome - to estimate various private capital levels' average treatment effects on public aid. We do so by using the GPS approach introduced by Hirano and Imbens (2004). More specifically, we first estimate the GPS using a generalised linear model; we then estimate the dose-response function (DRF), using a flexible parametric form for the regression function of the outcome, for treatment and the GPS. Ultimately, we attempt to identify the co-financing that a farm is willing to invest, by referencing quantitative changes to certain variables (e.g. private capital and public aid levels).

The remainder of this paper is organised as follows. Section 2 offers a short literature review on the crucial role of the RDP; it then analyses various funding evaluation methodologies. Section 3 briefly reviews and describes the approach utilised

Regional Statistics, Vol. 8. No. 2. 2018: 3-18; DOI: 10.15196/RS080209 
while leveraging the GPS. Then, section 4 presents the data we used and our results. Finally, section 5 summarises our conclusions.

\section{Literature review}

The RDP strategy takes up the three general objectives of the EU Regulation $1698 / 2005$ - namely, improving the competitiveness of the agricultural and forestry sectors, enhancing the environment and the countryside, and improving quality of life in rural areas and encouraging the diversification of their economic activity. These objectives are structured in terms of the 12 priorities identified in the National Strategic Plan (NSP). Within this framework, and in line with European and national guidelines, regional features and needs were identified in the context analysis work, to inform the specific objectives of each of the axes and the related measures. Ultimately, the endpoint was to pursue the following objectives: promote modernisation in the agri-food sector (i.e. at the farm and agri-food industry level, and to improve supply chain integration), promote sustainable agricultural development, safeguard forests and increase their surface area, improve the effectiveness of local governance that aims to develop strategies by which to increase local employment, promote economic diversification and improve services in less-favoured rural areas. The need to reduce the growth gap between affluent and industrialised areas has driven disadvantaged rural areas within the $\mathrm{EU}$ to implement local development policy tools from the initial structural programming stage (Casieri et al. 2010). The key factors contributing to the local success of the implemented tools surely derive from multi-level cooperation among various public, private, and civil stakeholders at local level (Perger 2016). From there, fluent communication among public and private organisations, not to mention the effective integration of objectives and policies, will prove essential for setting up appropriate governance patterns (Brunori-Rossi 2007).

The function of policies in facilitating or promoting private local development depends upon the institutional and social 'ability' of stakeholders in leveraging available policies (Mantino 2005). On the other hand, many factors that have contributed to the success (and failure) of EU programmes have often been attributed to their localisation in a specific territorial context (Lukić-Obad 2016). Several scholars have highlighted how agricultural plurality, diversification, and institutional networks can play critical roles in developing rural capital, one of the most important indicators of rurality (Lukić 2013, McAdam et al. 2016, McKitterick et al. 2016). The evaluation of public subsidies on the post-project income of a firm is often of great interest to policy-makers and academic researchers, and considerable interest has been evident in the recent literature (Xiaoyong-Cheng 2015). The governments of developing countries are increasingly turning to private investment as a means of stimulating rural development: in this way, private investment can be considered an

Regional Statistics, Vol. 8. No. 2. 2018: 3-18; DOI: 10.15196/RS080209 
engine of rural development (German et al. 2016), even if financial support from private creditors (i.e. banks) remains crucial (Badulescu et al. 2015). Researchers such as Lengyel and Leydesdorff (2015) show that foreign direct investment has had diverse effects on regional innovation systems. Finally, given the considerable role of private capital in enhancing rural development, its participation needs to be promoted through a number of possible channels (Wang-Sun 2016) - even if, historically, private capital has been disinclined to invest in agriculture in the absence of state support, and states have practiced varying degrees of regulation vis-à-vis private finance within the agricultural sector (Martin-Clapp 2015). Then, the process by which a policy's effects are evaluated becomes essential - not only in terms of policy implementation and more effective resource use, but also as a tool for redefining conceptual and operational approaches to policies.

Evaluations of the impact of policies require appropriate methodological responses. These responses can be usefully discussed under the rubric of two key issues: the impact of what and the impact on what. These two issues point to a key challenge in undertaking an impact evaluation - namely, the scope of the impact evaluation (Leeuw-Vaessen 2009). Researchers such as Bradley et al. (2010) stress that evaluations of rural development policies are mandatory for each member state during the programming period of their RDPs, with spot checks undertaken by the EC. Obviously, from the outcomes of previous programmes, it can be known that various techniques and temporal-distance phases have limitations that will impact future programming; nonetheless, an evaluation process can promote the quality and eventual success of an implemented policy. Starting with these main considerations that affect the evaluation process, and with a view to measuring the impacts, the EU regulation 1698/2005 acts as a general parameter that includes all the policies that aim to develop the food sector and the rural areas. Here, a multitude of tools are used to increase human capital; strengthen the structure of agricultural, food-quality, and agro-environmental policies; and diversify policies pertaining to productivity and improvements to quality of life in rural areas. These objectives are present in the strategic documents of the National Strategic Framework and the NSP, and they relate to the priority actions of the National Development Plan. The aforementioned regulation allows each EU member state to modulate its financial commitment to each thematic axis, so as to allocate financial resources in line with its own socioeconomic requirements for each intervention area. Each member state can also make adjustments on the basis of where needs are greatest - knowledge of which generally stems from $e x$ ante assessments drafted in the preliminary phase of each RDP. The need to control and audit, public spending has led in recent years to a constant deepening of evaluation with respect to public policies. The aim here has been not only to generate knowledge that can better inform decision-making and programme implementation, but also to support certain moral aspects (i.e. the use of public resources necessitates accountability and transparency).

Regional Statistics, Vol. 8. No. 2. 2018: 3-18; DOI: 10.15196/RS080209 
The scientific literature has paid particular attention to the issue of policy evaluation. There are at least two reasons for this growing interest (Esposti-Sotte 2013). First, the scientific community has recognised the legitimate challenge inherent in assessing policies, including those pertaining to economics and rural-based appraisals. This recognition relates to the fact that policy evolution - including that in the agricultural sector - has produced certain levels of procedural complexity (ImbensWooldridge 2009). These procedures are dedicated to the identification and development of multiple and heterogeneous methods and various assessment tools. Therefore, the evolution of the agricultural sector has resulted in considerable evaluation complexity, largely related to the number of objectives to be pursued and the number of objectives within each policy program. (EU member states have developed many new agricultural policies, and redesigned others with new and multiple objectives.) In this way, determining the tangible impacts of multiple and heterogeneous policy objectives has become an increasingly complex task.

Imbens and Wooldridge (2009) state that this policy-evolution process has brought about a new discipline that will present opportunities and, at the same time, a certain level of risk. Opportunities are identified in the course of undertaking research that relates to the development of policy assessment tools, and related risk becomes more apparent as policy evaluations leverage an increasingly restricted number of methodological approaches. The scientific community has confirmed the presence of this risk, in particular, over the previous decade, on account of its special attention to quasi-experimental methods and their application to evaluations of economic and rural-based outcomes. Additionally, researchers such as Alboiu et al. (2011) have shown that the use of enhanced eligibility criteria, the capture of more information, and the growth of awareness among farmers and local administration have improved access to credit. Thus, there is no single method by which to assess the effects of a considered intervention or policy; various techniques and statistical methods are available and chosen, depending on the data and information at hand and the evaluation questions for which one seeks answers.

The various evaluation approaches can be grouped into two main types, each of which features similar methods and evaluation processes. Let us look at each of these approaches, in turn.

1) The approach based on theory ('theory-based evaluation'). The methods of this type do not produce quantitative results; however, they do provide some answers to the initial research questions: Why do some programs work well while others do not? What are the effects of a given policy? For whose benefit are these policies enacted?, and In what context do these policies have an impact? These methods therefore aim to capture, through survey responses, the impact of a particular program or policy; this information quickly translates into data that can be useful in making political decisions, and in measuring the impact of a program or a public policy (Weiss 1998, Merlo 2014).

Regional Statistics, Vol. 8. No. 2. 2018: 3-18; DOI: 10.15196/RS080209 
2) The counterfactual approach. This approach - which is frequently leveraged in the field of economics - is a basic tool used to evaluate public policy. According to Lankoski and Ollikainen (2013), counterfactual analysis seeks to provide an answer to the question What would happen if...? In other words, counterfactual analysis is implemented by examining an unobservable case (i.e. the counterfactual) and comparing it to policies that can be evaluated: indeed, a comparison of the counterfactual and the real can assist in crafting estimates and in understanding the factors that explain policy effects. Public aid levels differ, depending on the level of private capital involved; therefore, to estimate the effects of public aid in relation to various private capital levels, the current study makes use of the GPS approach of Hirano and Imbens (2004). The propensity-score method is an increasingly popular means of undertaking estimations in the fields of agricultural and development economics (Lampach-Morawetz 2016). Other researchers have used GPS approach to estimate the capitalisation of a single-payment scheme in land values (Michalek et al. 2014) and to estimate net cherry returns and cherry yield (Ali et al. 2013). In the current study, based on the GPS method, a DRF is estimated to verify the effect of private capital on the probability that a given firm will be granted access to public aid.

\section{Materials and methods}

The firm-level data used in the current study were obtained from the Management Authority of the RDP of the Apulia Region. These data were drawn from the general database, which contains full information on those firms that had requested consideration for benefits by virtue of Measure 121, Axes I, of the RDP 2007-2013, through the first public call of 17 May 2012 no. 71. Parametric regression methods are used to investigate the relationship between private capital and public funds, as well as other variables (e.g. farm size, size of workforce, and cost), following a linear functional form:

$$
Y=\beta_{0}+\beta_{1} X_{1}+\beta_{2} X_{2}+\ldots \ldots \ldots+\beta_{m} X_{m} .
$$

Hirano and Imbens (2004) apply an extension of the propensity-score method to a setting with a continuous treatment, to investigate whether the effects of private capital (i.e. co-financing) on public subsidies differ, depending on the level of private capital involved. Imbens (2000) and Hirano and Imbens (2004) each generalise the unconfoundedness assumption for binary treatments (Rosenbaum-Rubin 1983) to multi-valued and continuous treatments. The key assumption is weak unconfoundedness:

$$
\mathrm{Y}(\mathrm{t}) \perp \mathrm{TX} \text { for all } \mathrm{t} \in \mathrm{T} \text {. }
$$


The assumption implies, conditional on the observed covariates $\mathrm{X}$, that the potential outcome $\mathrm{Y}(\mathrm{T})$ is independent of the level of treatment $\mathrm{T}$. This assumption makes the private capital random, by ruling out systematic selection into certain treatment levels. To make this assumption more plausible, the covariates X should include variables that determine the public selection of subsidised firms. Therefore, the average DRF, $\mu(\mathrm{t})=\mathrm{E}\left[\mathrm{Y}_{\mathrm{i}}(\mathrm{t})\right]$, can be obtained by estimating average outcomes in subpopulations separated by pre-treatment covariates and different levels of treatment. However, it is difficult to simultaneously adjust for multiple covariates. Let $r(t, x)$ be the conditional density of the treatment, given the covariates:

$$
\mathrm{r}(\mathrm{t}, \mathrm{x})=\mathrm{ft} \mid \mathrm{x}(\mathrm{t} \mid \mathrm{X}=\mathrm{x}) \text {. }
$$

Then, the GPS is $R=r(T, X)$. The GPS has a balancing property similar to the binary treatment case. Within strata with the same value of $r(t, X)$, the probability of $\mathrm{t}=\mathrm{T}$ is independent of the covariates $\mathrm{X}$ :

$$
\mathrm{X} \perp 1\{\mathrm{~T}=\mathrm{t}\} \mid \mathrm{r}(\mathrm{t}, \mathrm{X}) .
$$

Combined with the weak unconfoundedness assumption, the balancing property implies that assignment to the treatment level is unconfounded, given the GPS. Let $f \mathrm{~T}$ be the conditional probability of receiving $\mathrm{T}$. Then, for every $\mathrm{t}$ :

$$
f \mathrm{~T}(\mathrm{t} \mid \mathrm{r}(\mathrm{t}, \mathrm{X}), \mathrm{Y}(\mathrm{t}))=f \mathrm{~T}(\mathrm{t} \mid \mathrm{r}(\mathrm{t}, \mathrm{X})) .
$$

This result allows for the estimation of the average DRF, by using the GPS to remove selection bias associated with differences in the covariates. Following Hirano and Imbens (2004), bias removal via the GPS is carried out in two steps. In the first step of analysis, we estimate the expectation of the outcome as a function of the observed treatment level $(\mathrm{T})$ and the estimated GPS (R). Therefore, we first obtain:

$$
\beta(t, r)=E[Y(t) \mid r(t, X)=r]=E[Y \mid T=t, R=R] .
$$

In the second step, we estimate the value of the DRF at each specific treatment level, by averaging $\beta(t, r)$ over the GPS values at that particular level of treatment:

$$
\mu(\mathrm{t})=\mathrm{E}[\mathrm{Y}(\mathrm{t})]=\mathrm{E}[\beta(\mathrm{T}, \mathrm{r}(\mathrm{t}, \mathrm{X}))] .
$$

Hirano and Imbens (2004) stress that the regression function of Equation (5) does not have a causal interpretation; however, in calculating the average DRF in this way, Equation (6) does have one. GPS implementation relies on a number of assumptions, including parameterisations and functional forms. We employ a flexible parametric specification while paying considerable attention to testing the validity of these assumptions. First, a lognormal distribution is employed to model the conditional distribution of the treatment $\mathrm{T}$, given the covariates $\mathrm{X}$ :

$$
\ln \left(T_{i} \mid X_{i}\right) \sim N\left(\beta_{0}+\beta^{\prime}{ }_{1} X_{i}, \sigma^{2}\right) .
$$

If the lognormal distribution model is statistically approved, the estimated GPS can be obtained after estimating $\left(\beta_{0}, \beta_{1}, \sigma^{2}\right)$ by ordinary least squares:

Regional Statistics, Vol. 8. No. 2. 2018: 3-18; DOI: 10.15196/RS080209 


$$
\hat{R}_{i}=\frac{1}{\sqrt{2 \pi \sigma^{2}}} \exp \left(-\frac{1}{2 \sigma^{2}}\left(\ln \left(T_{i}\right)-\hat{\beta}_{0}-\hat{\beta}_{1} X_{i}\right)^{2}\right)
$$

Second, we model the conditional expectation of the outcome as a function of the observed treatment level and the estimated GPS. A quadratic approximation is employed:

$$
\mathrm{E}\left[\mathrm{Y}_{\mathrm{i}} \mid \mathrm{T}_{\mathrm{i}}, \mathrm{R}_{\mathrm{i}}\right]=\alpha_{0}+\alpha_{1} \mathrm{~T}_{\mathrm{i}}+\alpha_{2} \mathrm{~T}_{\mathrm{i}}^{2}+\alpha_{3} \mathrm{R}_{\mathrm{i}}+\alpha_{4} \mathrm{R}_{\mathrm{i}}^{2}+\alpha_{5} \mathrm{~T}_{\mathrm{i}}^{*} \mathrm{R}_{\mathrm{i}} .
$$

Finally, the value of the DRF at the treatment level t can be obtained by averaging the estimated parameter of Eq. (9) over the distribution of the GPS:

$$
E[Y(t)]=\frac{1}{N} \sum_{i=1}^{N}\left(\hat{\alpha_{0}}+\hat{\alpha}_{1} t+\hat{\alpha}_{2} t^{2}+\hat{\alpha_{3}} \hat{r}\left(t, x_{i}\right)^{2}+\hat{\alpha}_{4} \hat{r}\left(t, x_{i}\right)^{2}+\hat{\alpha_{5}} \hat{r}\left(t, x_{i}\right)^{2}\right)
$$

By repeating pattern Equation (11) at different treatment levels, we obtain an estimate of the full DRF. Furthermore, bootstrap methods are implemented to pattern standard errors and confidence intervals.

With regard to data collection, through a specific agreement between the Management Authority of the RDP of the Apulia Region and the Department of Economics at the University of Foggia, we gathered data pertaining to the measure in question - and which are not publicly available - including individual accounting items from the balance sheets that firms declared when submitting their application to participate in the public call over the 2007-2013 period. These data allow us to observe how 1,299 of 2,076 firms were actually granted benefits by virtue of Measure 121. Moreover, for each agricultural holding, the database provides the following information: a) amount of the proposed investment, b) public aid granted, c) the number of family and extra-family workers, d) revenue, e) production costs, and f) income levels prior to investment implementation.

Table 1 provides descriptions of the variables considered in this study. 
Table 1

\section{Descriptions of variables used in the current study}

\begin{tabular}{l|l}
\hline \multicolumn{1}{c|}{ Variable } & \multicolumn{1}{c}{ Description } \\
\hline Invest & $\begin{array}{l}\text { Total amount of investment proposed by the firm; derives from the sum of } \\
\text { public aid and private capital (EUR) } \\
\text { Amount associated with the contribution granted by the regional Authority } \\
\text { (EUR) } \\
\text { PublicAid }\end{array}$ \\
$\begin{array}{l}\text { Private capital } \\
\text { Farm size } \\
\text { No_Workforce } \\
\text { Revenues }\end{array}$ & $\begin{array}{l}\text { Size of the farm (ha) } \\
\text { Number of external workers (except those from the farmer's family) } \\
\text { Total amount of revenue from the firm's agricultural activity (EUR) } \\
\text { Total amount of production costs, from the firm's agricultural activity } \\
\text { (EUR) }\end{array}$ \\
Income derived from the firm's agricultural activity, as recorded before \\
the investment implementation (EUR)
\end{tabular}

To apply the GPS method, we must first model the conditional distribution of the treatment (in our case, private capital), given the covariate. Results of the Kolmogorov-Smirnov test for normality suggest that the transformed logarithm approximately follows a normal distribution; this is a commonly employed specification in the GPS literature (Hirano-Imbens 2004, Kluve et al. 2012).

\section{Results}

The GPS is defined as the conditional density of the actual treatment, given the observed covariates. To be effective, GPS methods should balance characteristics across treatment groups; the extent to which this has been achieved can be explored by comparing balance in the pre-treatment covariates before and after adjusting for the estimated GPS. In the current study, we apply the GPS method to investigate how the private capital an agricultural holding is willing to invest influences the amount of public aid received for project financing. Table 2 reports the results of our descriptive analysis. As one can see in the standard deviation values, the information we consider in our data is characterised by a high level of variability; this characteristic justifies making it a subject of econometric investigation. Furthermore, one can see the mean values of firm income (EUR45,009), farm size (41.97 ha), and workforce (15 units): broadly speaking, these figures suggest firms of very modest size and means. One can see that the mean investment amount is also modest (i.e. EUR158,182); as a result, even private capital and public aid quotas are quite small, and their mean values are about EUR83,000 and EUR75,000, respectively.

Regional Statistics, Vol. 8. No. 2. 2018: 3-18; DOI: 10.15196/RS080209 
Table 2

Descriptive analysis of variables

\begin{tabular}{l|r|r|r|r}
\hline \multicolumn{1}{c|}{ Variable } & Observations & Mean & $\begin{array}{r}\text { Standard } \\
\text { deviation }\end{array}$ & Skewness \\
\hline Invest (EUR) & 1,299 & 158,182 & $235,891.2$ & 5.191 \\
PublicAid (EUR) & 1,299 & $75,132.39$ & $112,767.2$ & 5.35 \\
Private capital (EUR) & 1,299 & $83,049.64$ & $126,640.9$ & 5.37 \\
Farm size (ha) & 1,299 & 41.97 & 58.14 & 5.08 \\
No_Workforce & 1,299 & 15.27 & 213.16 & 30.42 \\
Revenues (EUR) & 1,299 & $159,600.2$ & $197,457.8$ & 4.45 \\
Cost (EUR) & 1,299 & $114,590.2$ & $153,869.8$ & 4.96 \\
Income (EUR) & 1,299 & $45,009.95$ & $64,701.05$ & 4.81
\end{tabular}

Source: Authors' elaboration based on the Measure 121 database of the Apulia Region.

Table 3 reports the results of the regression model (Equation (1)).

Table 3

\section{Results of regression model analysis}

\begin{tabular}{l|r|r|r}
\hline \multicolumn{1}{c|}{ Source } & Sum of squares & $d f$ & Mean square \\
\hline Model & $1.4667 \mathrm{e}+13$ & 4 & $3.6667 \mathrm{e}+12$ \\
Residual & $1.8391 \mathrm{e}+12$ & 1,294 & $1.4212 \mathrm{e}+09$ \\
Total & $1.6506 \mathrm{e}+13$ & 1,298 & $1.2716 \mathrm{e}+10$ \\
\hline Number of obs. & 1,299 & & \\
$F(4.1294)$ & $2,579.97$ & & \\
Prob $>$ F & 0.0000 & & \\
R-squared & 0.8886 & & \\
Adjusted R-squared & 0.8882 & & \\
Root MSE & 37,699 & &
\end{tabular}

\begin{tabular}{l|r|r|r|r|r|r}
\hline \multicolumn{1}{c|}{ PublicAid } & Coefficient & Standard error & \multicolumn{1}{c|}{$t$} & $P>|t|$ & \multicolumn{2}{|c}{$95 \%$ Confidence interval } \\
\hline Private capital & 0.8455073 & 0.0089126 & 94.87 & 0.000 & 0.8280226 & 0.862992 \\
Farm size & 45.53136 & 19.58191 & 2.33 & 0.020 & 7.115588 & 83.94714 \\
No_Workforce & 9.924991 & 5.037065 & 1.97 & 0.049 & 0.0432821 & 19.8067 \\
Cost & -0.0364672 & 0.00772 & -4.72 & 0.000 & -0.0516124 & -0.0213221 \\
_Cons & $7,029.201$ & $1,461.723$ & 4.81 & 0.000 & $4,161.595$ & $9,896.807$
\end{tabular}


We then obtain the following equation.

$$
\mathrm{Y}=0.845 \mathrm{X}_{1}+45.53 \mathrm{X}_{2}+9.92 \mathrm{X}_{3}-0.036 \mathrm{X}_{4}
$$

where: $\mathrm{Y}=$ Public aid, $\mathrm{X}_{1}=$ Private capital, $\mathrm{X}_{2}=$ Farm size, $\mathrm{X}_{3}=$ Number of workforce, $\mathrm{X}_{4}=$ Cost.

As one can see, all variables considered in the regression model are statistically significant ( $\mathrm{p}$-value $<0.05$ ): in particular, private capital is highly significant ( $\mathrm{p}$ value $<0.001$ ). This indicates that the treatment variable (i.e. private capital) can be explained well by the covariates. In particular, in this case, we consider the firm size variable as a covariate. As Hirano and Imbens (2004) stress, estimated coefficients provide no direct meaning, but the results can be interpreted as a test of whether the covariates introduce any bias. In this way, using the estimated coefficients, the GPS estimation can be obtained via Equation (8). To assess whether the estimated GPS is adequate, we investigate how it affects the balance of the covariates. If the GPS is correctly estimated, the balancing properties should be satisfied. In the first step, we divide our range of observations into four treatment groups according to the quartile of the treatment variable; in the second step, we divide the range of private capital into four treatment groups. We then calculate the estimated GPS at the median of the treatment for all covariates within each group.

The balancing property (Table 4) is satisfied at a level lower than 0.001 .

Table 4

\section{Results of the balancing property}

\begin{tabular}{l|r|r|r|r|r|r}
\hline \multicolumn{1}{c|}{ PublicAid } & Coefficient & $\begin{array}{c}\text { Standard } \\
\text { error }\end{array}$ & \multicolumn{1}{c|}{$t$} & $P>|t|$ & \multicolumn{2}{|c}{$95 \%$ Confidence interval } \\
\hline Cprivate & 1.156118 & 0.0327807 & 35.27 & 0.000 & 1.091809 & 1.220427 \\
Cprivate_sq & $-3.18 \mathrm{e}-07$ & $3.11 \mathrm{e}-08$ & -10.21 & 0.000 & $-3.79 \mathrm{e}-07$ & $-2.57 \mathrm{e}-07$ \\
pscore & $55,861.78$ & $13,090.46$ & 4.27 & 0.000 & $30,181.15$ & $81,542.4$ \\
Cprivate_pscore & -0.7668125 & 0.1219935 & -6.29 & 0.000 & -1.006137 & -0.5274878 \\
_Cons & $-17,499.62$ & $5,145.415$ & -3.40 & 0.001 & $-27,593.8$ & $-7,405.436$
\end{tabular}

Our main purpose in this study, ultimately, is to estimate the DRF. Therefore, we first regress the outcome (public aid) on the treatment (private capital) and the GPS (see Equation (9)). As one can see in the Figure, the estimated DRF shows the relationship between private capital and treatment level. As seen in panel A of the Figure, the slope of the DRF approximates zero over the first range of treatment dose - in other words, for farms that employ a low level of private capital - but the slope strongly grows when the amount of private capital goes beyond the fourth interval.

Regional Statistics, Vol. 8. No. 2. 2018: 3-18; DOI: 10.15196/RS080209 


\section{Average DRF and 95\% confidence bands for public aid}

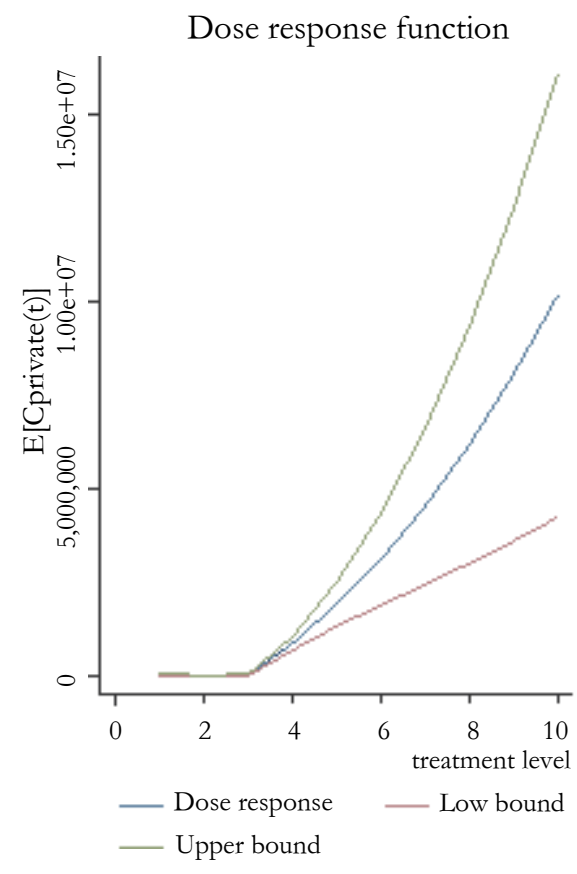

Confidence bounds at $95 \%$ level

Dose response function $=$ Linear prediction

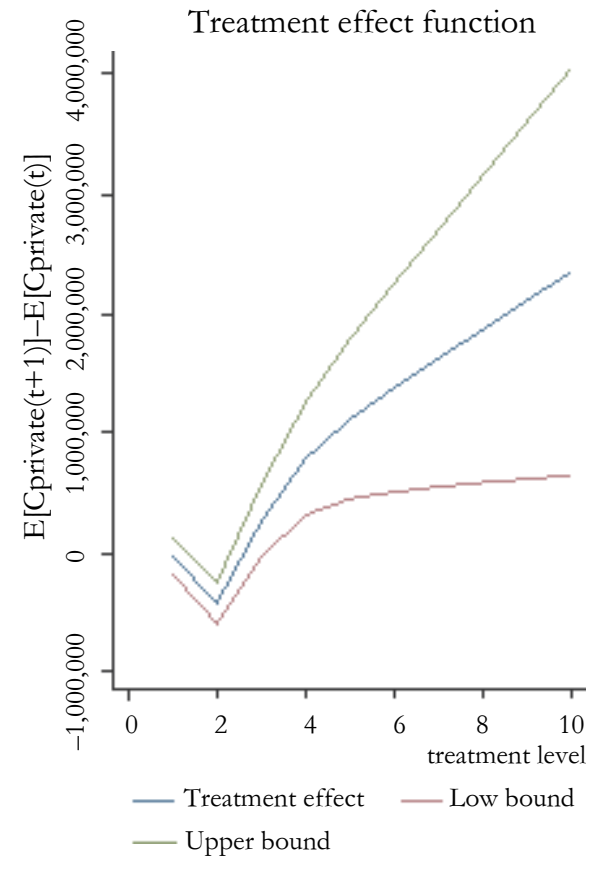

Confidence bounds at $95 \%$ level

Dose response function $=$ Linear prediction

\section{Conclusion and discussion}

This study applied a generalised propensity score (GPS) method to analyse the role of private capital in the process of modernising agricultural holdings, as seen in data pertaining to the Rural Development Programme (RDP) in the Apulia region of southern Italy over the 2007-2013 period. We introduced the general method applied by Hirano and Imbens (2004), who apply an extension to the propensity-score method in a continuous-treatment setting to investigate whether the effects of private capital on public subsidies differ with the level of private capital. Researchers such as Hirano and Imbens (2004) generalise the unconfoundedness assumption for binary treatments (Rosenbaum-Rubin 1983) to multi-valued and continuous treatments. Using data from the Management Authority of the RDP of the Apulia Region, we saw that 1,299 of the 2,076 firms who had applied for benefits through Measure 121 actually gained access to this funding. Using these data, we found that holding private capital increases the probability of firms receiving public aid benefits. Our study is amongst the first to investigate the role of private capital that an agricultural holding is willing to invest, in relation to the amount of public aid it will receive in support of its modernisation. 
The results of this study are relevant to both the Apulia region and the national level: they speak about the function of policies in facilitating or promoting private local development, and how this function is contingent upon the institutional and social 'ability' of stakeholders to make use of available policies (Mantino 2005). On the other hand, as mentioned, evaluations of public subsidies and how they affect post-project firm income are often of interest to policy-makers and academic researchers, and interest in this area is seen in the literature (Xiaoyong-Cheng 2015). The governments of developing countries increasingly look to private investment as a means of stimulating rural development. For this reason, it can be considered a driver of rural development (German et al. 2016), even if financial support from private creditors (i.e. banks) remains crucial (Badulescu et al. 2015).

In accordance with the literature, and as Edmiston (2007) demonstrates, there is no clear evidence that small businesses are more effective innovators. Nonetheless, small firms create the majority of net new jobs and are critical innovators, and so efforts to encourage the formation and growth of small enterprises are likely sensible in most cases. Among EU member states, there is a great demand for public aid in the area of rural development policy, and such policies will push firms to make new investments that will, ultimately, have tangible economic effects at the regional and national levels.

Measure 121 (Axes I) of the most recent RDP (i.e. 2007-2013) has been essential to the success of several firms, within regional, national, and European contexts. It has had positive and significant effects on medium and large firms in particular, and one could say that supporting small firms is likely a good growth strategy for both the region and the nation. Therefore, our results suggest public policies and rural development policies by which small firms - which are more in need of benefits - could secure funding.

Indeed, the European policy strategy should help provide more economic aid for small firms, to help them grow, even when there is a relative dearth of private resources. Such strategies would help in defining the effectiveness of a regional policy and preclude the waste of economic resources; it may also encourage the use of tax abatements or capital investments from banks, in addition to any private capital. In any case, further theoretical research is needed.

The results of this work could inform future rural development policy at the regional and national levels. In this way, it could contribute to the crafting of public policy and to the creation of more instruments by which various projects (e.g. investment projects related to agricultural holdings that have small private capital amounts) could increase their probability of securing financing.

Regional Statistics, Vol. 8. No. 2. 2018: 3-18; DOI: 10.15196/RS080209 


\section{Acknowledgements}

We are grateful for financial support from the Management Authority of the Rural Development Programme of the Apulia Region. We thank the editor and an anonymous reviewer for their constructive comments, which helped us improve this paper.

\section{REFERENCES}

Alboiu, C.-Kuliesis, G.-SAlengaite, D. (2011): The impact of Rural Development Program on agriculture and business/rural development in Lithuania and Romania: a mirror situation Agricultural Economics and Rural Development, New Series 8 (1): 77-90.

Ali, A.-Sharif, M.-MAHMOOD, K.-AKmal, N. (2013): Determinants of cherry production and marketing in Pakistan: A propensity score matching approach Agricultural Economics Review 14 (1): 45-58.

Badulescu, D.-Giurgiu, A.-Istudor, N.-BAdulescu, A. (2015): Rural tourism development and financing in Romania: A supply-side analysis Agricultural Economics (Czеch Republic) 61 (2): 72-80. https://doi.org/10.17221/94/2014-AGRICECON

Bradley, D-Dwyer, J.-Hill, B. (2010): The Evaluation of Rural Development Policy in the EU EuroChoices 9: 15-20. https://doi.org/10.1111/j.1746-692X.2010.00148.x

BRUNORI, G.-RossI, A. (2007): Differentiating countryside: Social representations and governance patterns in rural areas with high social density: The case of chianti, Italy Journal of Rural Studies 23 (2): 183-205. https://doi.org/10.1016/j.jrurstud.2006.10.001

CAsieri, A.-NAZZaro, C.-Roselli L. (2010): Trust building and social capital as development policy tools in rural areas. An empirical analysis: the case of the LAG CDNISAT New Medit 1: 24-30.

EDmiston, K. D. (2007): The Role of Small and Large Businesses in Economic Development SSRN Electronic Journal 92 (Q II): 73-97. http://dx.doi.org/10.2139/ssrn.993821.

Esposti, R.-SotTe, F. (2013): Evaluating the Effectiveness of Agricultural and Rural Policies: An Introduction European Review of Agricultural Economics 40 (4): 535-539. https://doi.org/10.1093/erae/jbt014

European CounCIL (2005): Council Regulation (EC) no. 1698. Support for rural development by the European Agricultural Fund for Rural Development

EUROPEAN COURT OF AUDITORS (2012): Targeting of aid for the modernization of agricultural holdings? Special Report No. 8.

German, L.-CAvane, E.-Sitoe, A.-BragA, C. (2016): Private investment as an engine of rural development: A confrontation of theory and practice for the case of Mozambique Land use Policy 52: 1-14. https://doi.org/10.1016/j.landusepol.2015.11.012

Regional Statistics, Vol. 8. No. 2. 2018: 3-18; DOI: 10.15196/RS080209 
Hirano, K.-Imbens, G. (2004): The propensity score with continuous treatment In: GELman, A.-Meng, X.-L. (Eds.): Applied Bayesian Modelling and Causal Inference from Missing Data Perspectives pp. 73-84., Wiley, New York.

ImBENS, G. (2000): The role of the propensity score in estimating dose-response functions Biometrika 87 (3): 706-710.

Imbens, G. W.-Wooldridge, J. M. (2009): Recent Developments in the Econometrics of Program Evaluation Journal of Economic Literature 47 (1): 5-86. http://dx.doi.org/10.1257/jel.47.1.5

Kluve, J.-Schneider, H.-UhlendorfF, A.-ZhAO, Z. (2012): Evaluating continuous training programs using the Generalized Propensity Score Journal of the Royal Statistical Society, Series A 175 (2): 587-617. https://doi.org/10.1111/j.1467985X.2011.01000.x

LAMPACH, N.-MORAWETZ, U. B. (2016): Credibility of propensity score matching estimates. an example from fair trade certification of coffee producers Applied Economics 48 (44): 4227-4237. https://doi.org/10.1080/00036846.2016.1153795.

Lankoski, J.-Oldikainen, M. (2013): Counterfactual Approach for Assessing Agrienvironmental Policy: The Case of the Finnish Water Protection Policy Review of Agricultural and Environmental Studies 94 (2): 165-193.

LECHNER M. R. (2001): Identification and estimation of causal effects of multiple treatments under the conditional independence assumption In: LECHNER, M. R.Pfeiffereds, F. (Eds.). Econometric Evaluation of Labour Market Policies pp. 43-58., Physica, Heidelberg.

LEEUW, F.-VAESSEN, J. (2009): Impact evaluations and development: NONIE guidance on impact evaluation The World Bank, Washington, DC.

LENGYEL,B.-LEYDESDORFF, L. (2015): The Effects of FDI on Innovation Systems in Hungarian Regions: Where is the Synergy Generated? Regional Statistics 5 (1): 3-24. https://doi.org/10.15196/RS05101

LukesCH, R.-SCHUH, B. (2010): Approaches for Assessing the Impacts of the Rural Development Programmes in the Context of Multiple Intervening Factors European Evaluation Network for Rural Development, Brussels.

LuKIĆ, A. (2013): Tourism, farm diversification and plurality of rurality: Case study of Croatia European Countryside 5 (4): 356-376. https://doi.org/10.2478/euco-2013-0023

LuKić, A.-OBAD, O. (2016): New actors in rural development - the LEADER approach and projectification in rural Croatia Sociologija i Prostor 54 (1): 71-90. https://doi.org/10.5673/sip.54.1.4

Mantino, F. (2005): Rural development in Europe: Approaches and future perspectives. New approaches to rural policy: Lessons from around the world pp. 69-87., OECD, Washington. https://dx.doi.org/10.1787/9789264010130-en

MARTIN, S. J.-CLAPP, J. (2015): Finance for agriculture or agriculture for finance? Journal of Agrarian Change 15 (4): 549-559. https://doi.org/10.1111/joac.12110

MATERIA V. C.-PASCUCCI S.-KOLYMPIRIS C. (2015): Understanding the selection processes of public research projects in agriculture: The role of scientific merit Food Policy 56: 87-99. https://doi.org/10.1016/j.foodpol.2015.08.003

Regional Statistics, Vol. 8. No. 2. 2018: 3-18; DOI: 10.15196/RS080209 
MCADAM, M.-MCADAM, R.-DunN, A.-MCCALL, C. (2016): Regional horizontal networks within the SME agri-foodagri-food sector: An innovation and social network perspective Regional Studies 50 (8): 1316-1329. https://doi.org/10.1080/00343404.2015.1007935

MCKitTERiCK, L.-QuinN, B.-MCADAM, R.-DunN, A. (2016): Innovation networks and the institutional actor-producer relationship in rural areas: The context of artisan food production Journal of Rural Studies 48: 41-52. https://doi.org/10.1016/j.jrurstud.2016.09.005

MERLO, G. (2014): La programmazione sociale: principi, metodi e strumenti Carocci Faber, Rome.

MichaleK, J.-Ciaian, P.-KanCs, A. (2014): Capitalization of the single payment scheme into land value: Generalized propensity score evidence from the European Union Land Economics 90 (2): 260-289. https://doi.org/10.3368/le.90.2.260

Perger, E. (2016): Local Responses to the Structural Changes of National Development Policy in Hungarian Rural Regions Eastern European Countryside 22 (1): 69-83. https://doi.org/10.1515/eec-2016-0004

Rosenbaum, P. R.-Rubin, D. B. (1983): The central role of the propensity score in observational studies for causal effects Biometrika 70 (1): 41-55. https://doi.org/10.1093/biomet/70.1.41

WANG, Z.-SUN, S. (2016): Transportation infrastructure and rural development in China China Agricultural Economic Review 8 (3): 516-525. https://doi.org/10.1108/CAER-09-2015-0115.

WEISS, C. (1998): Evaluation: methods for studying programs and policies Prentice Hall, New York.

XiAoyong, D.-CHeng, L. (2015): The effect of public subsidies on corporate R\&D investment: An application of the generalized propensity score Technological Forecasting and Social Change 90 (Part B): 410-419.

https://doi.org/10.1016/j.techfore.2014.04.014

Regional Statistics, Vol. 8. No. 2. 2018: 3-18; DOI: 10.15196/RS080209 